Supporting Information for

\title{
DNA-Programmed Bimodal 2D Assembly of Differently Sized Nanoparticles via Folding of Precursory Circular Chains
}

\author{
Tzung-Ying Yang, ${ }^{\dagger, *}$ Li Yu, ${ }^{\dagger, *}$ Yoshitsugu Akiyama, ${ }^{\star \&}$ Tohru Takarada, ${ }^{*, *}$ and Mizuo Maeda ${ }^{\dagger, *}$ \\ ${ }^{\dagger}$ Department of Advanced Materials Science, Graduate School of Frontier Sciences, \\ The University of Tokyo \\ 5-1-5 Kashiwano-ha, Kashiwa, Chiba 277-8561, Japan
}

${ }^{\ddagger}$ Bioengineering Laboratory, RIKEN Cluster for Pioneering Research

2-1 Hirosawa, Wako, Saitama 351-0198, Japan

${ }^{\S}$ Faculty of Industrial Science and Technology, Tokyo University of Science
102-1 Tomino, Oshamambe-cho, Yamakoshi-gun, Hokkaido 049-3514, Japan

CONTENTS

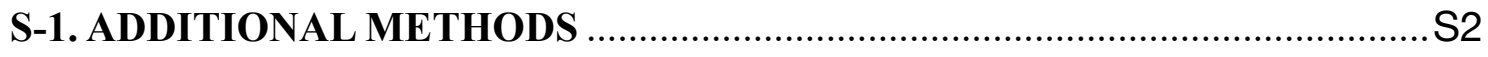

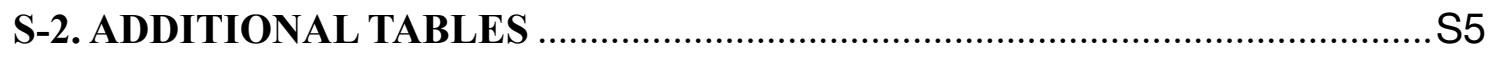

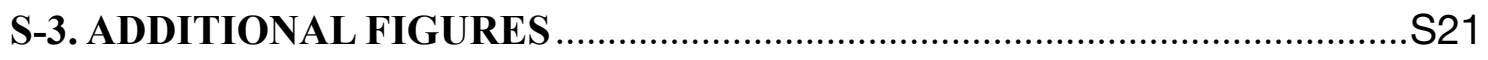




\section{S-1. ADDITIONAL METHODS}

\section{Surface Modification of 5 nm-AuNP with ssDNA}

Initially, the AuNP was stabilized with BSPP by heating at $50^{\circ} \mathrm{C}$ for $1 \mathrm{~h}$. Next, anchor DNAI was treated with TCEP to produce a dithiol group at the $3^{\prime}$-end. Then, the anchor DNA-I solution was added to a BSPP-AuNP dispersion in $0.5 \times \mathrm{TBE}$ buffer at a 1:1 molar ratio, followed by incubation at $50^{\circ} \mathrm{C}$ for $1 \mathrm{~h}$. To this dispersion, 4 equiv (relative to anchor DNAI) of extender DNA-I was added. The obtained mixture was incubated at $60^{\circ} \mathrm{C}$ for $5 \mathrm{~min}$, and subsequently at room temperature for $1 \mathrm{~h}$. To obtain the anchor-DNA-I-monoconjugated AuNP, the mixture supplemented with 5\% v/v glycerol (final concentration) was subjected to $3 \%$ agarose gel electrophoresis $\left(135 \mathrm{~V}, 30 \mathrm{~min}\right.$, and $\left.4^{\circ} \mathrm{C}\right)$ using a Mupid-eXU electrophoresis system (Mupid). After the adjacent downstream area of the second band from the bottom was cut out, an additional electrophoresis was performed so that the anchor-DNAI-monoconjugated AuNP with extender DNA-I was extracted into the hole. The disperse medium of the extracted anchor-DNA-I-monoconjugated AuNPs with extender DNA-I was replaced by $0.5 \times \mathrm{TBE}$ buffer containing $100 \mathrm{mM} \mathrm{NaCl}$ and $1 \mathrm{mg} / \mathrm{mL}$ BSPP dehydrate dipotassium salt via centrifugation at $21900 \times g$ for $90 \mathrm{~min}$ and was concentrated to $1 \mu \mathrm{M}$. Then, 4 equiv (relative to the AuNP) of remover DNA-I was added to the AuNP dispersion to release the extender DNA-I from the AuNP surface via the strand exchange. The obtained dispersion was incubated at $60^{\circ} \mathrm{C}$ for $5 \mathrm{~min}$, and then allowed to stand at room temperature

for $1 \mathrm{~h}$. The resulting dispersion was centrifuged at $21900 \times \mathrm{g}$ for $90 \mathrm{~min}$, followed by resuspension of the sediment in $0.5 \times \mathrm{TBE}$ buffer containing $100 \mathrm{mM} \mathrm{NaCl}$ and $1 \mathrm{mg} / \mathrm{mL}$ BSPP dehydrate dipotassium salt. This step was repeated three times to remove the excess 
DNA. The anchor-DNA-I-monoconjugated AuNP was further modified with cover DNA by the salt-aging method. After 500 equiv (relative to the AuNP) of cover DNA was added, the dispersion was incubated at room temperature for $3 \mathrm{~h}$. Subsequently, the $\mathrm{NaCl}$ concentration was gradually increased at intervals of $45 \mathrm{mM}$, and finally brought to $300 \mathrm{mM}$ over $3 \mathrm{~h}$. The

excess cover DNA was removed by centrifugation at $21900 \times g$ for $90 \mathrm{~min}$, followed by resuspension of the sediment in $0.5 \times \mathrm{TBE}$ buffer containing $100 \mathrm{mM} \mathrm{NaCl}$ and $1 \mathrm{mg} / \mathrm{mL}$ BSPP dehydrate dipotassium salt. This purification step was repeated three times. The obtained ssDNA-AuNP monomers were resuspended in the same buffer $(2 \mu \mathrm{M})$.

\section{Surface Modification of $15 \mathrm{~nm}$-AuNP with ssDNA}

The procedure was the same as that for $5 \mathrm{~nm}$-AuNP, except for the following points. (i) The anchor DNA-I, extender DNA-I, and remover DNA-I were replaced with anchor DNA-II, extender DNA-II, and remover DNA-II, respectively. (ii) The molar ratio of anchor DNA-II and BSPP-AuNP was 2:1. (iii) The $0.5 \times \mathrm{TBE}$ buffer containing $25 \mathrm{mM} \mathrm{NaCl}$ and 0.33 $\mathrm{mg} / \mathrm{mL}$ BSPP dehydrate dipotassium salt was used. (iv) The centrifugation was performed at $14000 \mathrm{rpm}$ for $30 \mathrm{~min}$. (v) The anchor-DNA-II-monoconjugated AuNP with extender DNAII was concentrated to $250 \mathrm{nM}$. (vi) For the salt-aging procedure, 2000 equiv of cover DNA was used. (vii) The obtained ssDNA-AuNP monomers were resuspended to provide the concentration of $500 \mathrm{nM}$. 


\section{Determination of DNA Number on the AuNP Surface}

The dispersion of ssDNA-AuNPs was diluted with $1 \times$ Tris-EDTA (TE) buffer to be $80 \mathrm{nM}$ for $5 \mathrm{~nm}$-AuNP and $5 \mathrm{nM}$ for $15 \mathrm{~nm}$-AuNP. The $1 \times$ TE buffer containing $20 \mathrm{mM}$ DTT was also prepared. The aliquots of two solutions (60 $\mu \mathrm{L}$ each) described above were mixed, and then incubated at $50^{\circ} \mathrm{C}$ for $16 \mathrm{~h}$. After the centrifugation at $14000 \mathrm{rpm}$ for $25 \mathrm{~min}$ at $10^{\circ} \mathrm{C}$, the supernatant $(100 \mu \mathrm{L})$ was pipetted off and mixed with an aqueous solution of OliGreen (Invitrogen) in $1 \times \mathrm{TE}$ buffer $(100 \mu \mathrm{L})$. The resultant mixture was incubated at room temperature for $10 \mathrm{~min}$. The fluorescence intensity was measured using a multilabel microplate reader 2030 ARVO X Series (PerkinElmer) with excitation at $485 \mathrm{~nm}$ and recording emission at $535 \mathrm{~nm}$. The number of DNA strands immobilized on each AuNP was determined by using calibration curves. The mean and the standard deviation were obtained from three independent experiments.

\section{UV-Vis Spectroscopy}

A dispersion of ssDNA-AuNP hetero-assemblies (1.6 nM of both $5 \mathrm{~nm}$ - and $15 \mathrm{~nm}$-AuNPs) and complementary DNA or terminal-base-substituted DNA (16 equiv of the total amount of cover DNA) in $0.5 \times \mathrm{TBE}$ buffer $(100 \mu \mathrm{L})$ containing $150 \mathrm{mM}$ or $300 \mathrm{mM} \mathrm{NaCl}$ was incubated at room temperature for $30 \mathrm{~min}$. Extinction spectra were obtained with a Cary 50 UV-vis spectrophotometer (Varian). 


\section{S-2. ADDITIONAL TABLES}

Table S1. Base Sequences of Short DNA Strands Used to Modify AuNP Surfaces

\begin{tabular}{|c|c|c|}
\hline code & length (nt) & sequence $\left(5^{\prime} \text { to } 3^{\prime}\right)^{a}$ \\
\hline \multirow{2}{*}{ anchor DNA-I } & \multirow{2}{*}{59} & TCACGCACACTAAGGGAAGTAGCCGCACATCTGAG \\
\hline & & TATCTTTTTCGCAACAATAACTGA-DTT \\
\hline \multirow{2}{*}{ anchor DNA-II } & \multirow{2}{*}{59} & TACACCGTTCTACATCACTTTCTCGTATAACATTT \\
\hline & & ACACCTTTTCGCAACAATAACTGA-DTT \\
\hline extender DNA-I & 70 & CCCTTAGTGTGCGTGA- $(\mathrm{T})_{54}$ \\
\hline extender DNA-II & 70 & GATGTAGAACGGTGTA- $(\mathrm{T})_{54}$ \\
\hline remover DNA-I & 70 & $(\mathrm{~A})_{54}$-TCACGCACACTAAGGG \\
\hline remover DNA-II & 70 & $(\mathrm{~A})_{54}$-TACACCGTTCTACATC \\
\hline cover DNA & 16 & TGACACTGCCTCCTAA-SH \\
\hline complementary DNA & 16 & TTAGGAGGCAGTGTCA \\
\hline terminal-base-substituted DNA & 16 & TTAGGAGGCAGTGTCT \\
\hline
\end{tabular}

${ }^{a}$ The segment of anchor DNA for duplex formation with adaptor DNA is highlighted with underline. DTT and SH denote the dithiol and monothiol groups, respectively. The mismatched terminal base is highlighted in red. 
Table S2. Base Sequences of Adaptor DNA-I

\begin{tabular}{|c|c|c|}
\hline code & length (nt) & sequence $\left(5^{\prime}\right.$ to $\left.3^{\prime}\right)$ \\
\hline adaptor DNA-I-1 & 70 & $\begin{array}{l}\text { TGCGGCTACTTCCCTTAGTGTGCGTGA-TTT- } \\
\text { AGCATTCCACAGACAGCCCTCATAGTTAGCGTAACGATCT } \\
\text { The segments for the duplex formation with anchor DNA-I and } \\
\text { scaffold DNA are highlighted with underline and in red, } \\
\text { respectively. }\end{array}$ \\
\hline adaptor DNA-I-2 & 70 & $\begin{array}{l}\text { TGCGGCTACTTCCCTTAGTGTGCGTGA-TTT - } \\
\text { GTAAATGAATTTTCTGTATGGGATTTTGCTAAACAACTTT }\end{array}$ \\
\hline adaptor DNA-I-3 & 70 & $\begin{array}{l}\text { TGCGGCTACTTCCCTTAGTGTGCGTGA-TTT- } \\
\text { AAGGAACAACTAAAGGAATTGCGAATAATAATTTTTTCAC }\end{array}$ \\
\hline adaptor DNA-I-4 & 70 & $\begin{array}{l}\text { TGCGGCTACTTCCCTTAGTGTGCGTGA-TTT- } \\
\text { AAAAGGAGCCTTTAATTGTATCGGTTTATCAGCTTGCTTT }\end{array}$ \\
\hline adaptor DNA-I-5 & 70 & $\begin{array}{l}\text { TGCGGCTACTTCCCTTAGTGTGCGTGA-TTA- } \\
\text { ACCGATAGTTGCGCCGACAATGACAACAACCATCGCCCAC }\end{array}$ \\
\hline adaptor DNA-I-6 & 70 & $\begin{array}{l}\text { TGCGGCTACTTCCCTTAGTGTGCGTGA-TTT - } \\
\text { GCTTGCAGGGAGTTAAAGGCCGCTTTTGCGGGATCGTCAC }\end{array}$ \\
\hline adaptor DNA-I-7 & 70 & $\begin{array}{l}\text { TGCGGCTACTTCCCTTAGTGTGCGTGA-TTT - } \\
\text { CGAGGGTAGCAACGGCTACAGAGGCTTTGAGGACTAAAGA }\end{array}$ \\
\hline adaptor DNA-I-8 & 70 & $\begin{array}{l}\text { TGCGGCTACTTCCCTTAGTGTGCGTGA-TTT - } \\
\text { CGGGTAAAATACGTAATGCCACTACGAAGGCACCAACCTA }\end{array}$ \\
\hline adaptor DNA-I-9 & 70 & $\begin{array}{l}\text { TGCGGCTACTTCCCTTAGTGTGCGTGA-TTT - } \\
\text { AAACACTCATCTTTGACCCCCAGCGATTATACCAAGCGCG }\end{array}$ \\
\hline adaptor DNA-I-10 & 70 & $\begin{array}{l}\text { TGCGGCTACTTCCCTTAGTGTGCGTGA-TTT - } \\
\text { ATCGCCTGATAAATTGTGTCGAAATCCGCGACCTGCTCCA }\end{array}$ \\
\hline adaptor DNA-I-11 & 70 & $\begin{array}{l}\text { TGCGGCTACTTCCCTTAGTGTGCGTGA-TTT - } \\
\text { CGGTCAATCATAAGGGAACCGAACTGACCAACTTTGAAAG }\end{array}$ \\
\hline adaptor DNA-I-12 & 70 & $\begin{array}{l}\text { TGCGGCTACTTCCCTTAGTGTGCGTGA-TTT - } \\
\text { GCGCATAGGCTGGCTGACCTTCATCAAGAGTAATCTTGAC }\end{array}$ \\
\hline adaptor DNA-I-13 & 70 & $\begin{array}{l}\text { TGCGGCTACTTCCCTTAGTGTGCGTGA-TTT- } \\
\text { AACGTAACAAAGCTGCTCATTCAGTGAATAAGGCTTGCCC }\end{array}$ \\
\hline adaptor DNA-I-14 & 70 & $\begin{array}{l}\text { TGCGGCTACTTCCCTTAGTGTGCGTGA-TTT - } \\
\text { AATTGGGCTTGAGATGGTTTAATTTCAACTTTAATCATTG }\end{array}$ \\
\hline
\end{tabular}




\begin{tabular}{|c|c|c|}
\hline \multirow{2}{*}{ adaptor DNA-I-15 } & \multirow{2}{*}{70} & TGCGGCTACTTCCCTTAGTGTGCGTGA-TTT- \\
\hline & & TGGCTCATTATACCAGTCAGGACGTTGGGAAGAAAAATCT \\
\hline \multirow{2}{*}{ adaptor DNA-I-16 } & \multirow{2}{*}{70} & TGCGGCTACTTCCCTTAGTGTGCGTGA-TTT- \\
\hline & & ACATTATTACAGGTAGAAAGATTCATCAGTTGAGATTTAG \\
\hline \multirow{2}{*}{ adaptor DNA-I-17 } & \multirow{2}{*}{70} & TGCGGCTACTTCCCTTAGTGTGCGTGA-TTT- \\
\hline & & CATAACGCCAAAAGGAATTACGAGGCATAGTAAGAGCAAC \\
\hline \multirow{2}{*}{ adaptor DNA-I-18 } & \multirow{2}{*}{70} & TGCGGCTACTTCCCTTAGTGTGCGTGA-TTT- \\
\hline & & ACGATAAAAACCAAAATAGCGAGAGGCTTTTGCAAAAGAA \\
\hline \multirow{2}{*}{ adaptor DNA-I-19 } & \multirow{2}{*}{70} & TGCGGCTACTTCCCTTAGTGTGCGTGA-TTT- \\
\hline & & TGTTTAGACTGGATAGCGTCCAATACTGCGGAATCGTCAT \\
\hline \multirow{2}{*}{ adaptor DNA-I-20 } & \multirow{2}{*}{70} & TGCGGCTACTTCCCTTAGTGTGCGTGA-TTT- \\
\hline & & CTTTAAACAGTTCAGAAAACGAGAATGACCATAAATCAAA \\
\hline \multirow{2}{*}{ adaptor DNA-I-21 } & \multirow{2}{*}{70} & TGCGGCTACTTCCCTTAGTGTGCGTGA-TTT- \\
\hline & & GTCAGAAGCAAAGCGGATTGCATCAAAAAGATTAAGAGGA \\
\hline \multirow{2}{*}{ adaptor DNA-I-22 } & \multirow{2}{*}{70} & TGCGGCTACTTCCCTTAGTGTGCGTGA-TTT- \\
\hline & & TTAATTCGAGCTTCAAAGCGAACCAGACCGGAAGCAAACT \\
\hline \multirow{2}{*}{ adaptor DNA-I-23 } & \multirow{2}{*}{70} & TGCGGCTACTTCCCTTAGTGTGCGTGA-TTT- \\
\hline & & TTAATTGCTCCTTTTGATAAGAGGTCATTTTTGCGGATGG \\
\hline \multirow{2}{*}{ adaptor DNA-I-24 } & \multirow{2}{*}{70} & TGCGGCTACTTCCCTTAGTGTGCGTGA-TTT- \\
\hline & & CTGTAGCTCAACATGTTTTAAATATGCAACTAAAGTACGG \\
\hline \multirow{2}{*}{ adaptor DNA-I-25 } & \multirow{2}{*}{70} & TGCGGCTACTTCCCTTAGTGTGCGTGA-TTT- \\
\hline & & GTTGATTCCCAATTCTGCGAACGAGTAGATTTAGTTTGAC \\
\hline \multirow{2}{*}{ adaptor DNA-I-26 } & \multirow{2}{*}{70} & TGCGGCTACTTCCCTTAGTGTGCGTGA-TTT- \\
\hline & & TAACCTGTTTAGCTATATTTTCATTTGGGGCGCGAGCTGA \\
\hline \multirow{2}{*}{ adaptor DNA-I-27 } & \multirow{2}{*}{70} & TGCGGCTACTTCCCTTAGTGTGCGTGA-TTT- \\
\hline & & AGTAGCATTAACATCCAATAAATCATACAGGCAAGGCAAA \\
\hline \multirow{2}{*}{ adaptor DNA-I-28 } & \multirow{2}{*}{70} & TGCGGCTACTTCCCTTAGTGTGCGTGA-TTT- \\
\hline & & TCAGAGCATAAAGCTAAATCGGTTGTACCAAAAACATTAT \\
\hline \multirow{2}{*}{ adaptor DNA-I-29 } & \multirow{2}{*}{70} & TGCGGCTACTTCCCTTAGTGTGCGTGA-TTT- \\
\hline & & ССTTTATTTCAACGCAAGGATAAAAATTTTTAAGAACCCTC \\
\hline \multirow{2}{*}{ adaptor DNA-I-30 } & \multirow{2}{*}{70} & TGCGGCTACTTCCCTTAGTGTGCGTGA-TTT- \\
\hline & & ATGTGTAGGTAAAGATTCAAAAGGGTGAGAAAGGCCGGAG \\
\hline
\end{tabular}




\begin{tabular}{|c|c|c|}
\hline \multirow{2}{*}{ adaptor DNA-I-31 } & \multirow{2}{*}{70} & TGCGGCTACTTCCCTTAGTGTGCGTGA-TTT- \\
\hline & & TCAACCGTTCTAGCTGATAAATTAATGCCGGAGAGGGTAG \\
\hline \multirow{2}{*}{ adaptor DNA-I-32 } & \multirow{2}{*}{70} & TGCGGCTACTTCCCTTAGTGTGCGTGA-TTT- \\
\hline & & TCAGGTCATTGCCTGAGAGTCTGGAGCAAACAAGAGAATC \\
\hline \multirow{2}{*}{ adaptor DNA-I-33 } & \multirow{2}{*}{70} & TGCGGCTACTTCCCTTAGTGTGCGTGA-TTT- \\
\hline & & GTCAATCATATGTACCCCGGTTGATAATCAGAAAAGCCCC \\
\hline \multirow{2}{*}{ adaptor DNA-I-34 } & \multirow{2}{*}{70} & TGCGGCTACTTCCCTTAGTGTGCGTGA-TTT- \\
\hline & & ATTTAAATTGTAAACGTTAATATTTTGTTAAAATTCGCAT \\
\hline \multirow{2}{*}{ adaptor DNA-I-35 } & \multirow{2}{*}{70} & TGCGGCTACTTCCCTTAGTGTGCGTGA-TTT- \\
\hline & & TTAACCAATAGGAACGCCATCAAAAATAATTCGCGTCTGG \\
\hline \multirow{2}{*}{ adaptor DNA-I-36 } & \multirow{2}{*}{70} & TGCGGCTACTTCCCTTAGTGTGCGTGA-TTT- \\
\hline & & TTAAATGTGAGCGAGTAACAACCCGTCGGATTCTCCGTGG \\
\hline \multirow{2}{*}{ adaptor DNA-I-37 } & \multirow{2}{*}{70} & TGCGGCTACTTCCCTTAGTGTGCGTGA-TTT- \\
\hline & & GATAGGTCACGTTGGTGTAGATGGGCGCATCGTAACCGTG \\
\hline \multirow{2}{*}{ adaptor DNA-I-38 } & \multirow{2}{*}{70} & TGCGGCTACTTCCCTTAGTGTGCGTGA-TTT- \\
\hline & & AGTATCGGCCTCAGGAAGATCGCACTCCAGCCAGCTTTCC \\
\hline \multirow{2}{*}{ adaptor DNA-I-39 } & \multirow{2}{*}{70} & TGCGGCTACTTCCCTTAGTGTGCGTGA-TTT- \\
\hline & & GCAAAGCGCCATTCGCCATTCAGGCTGCGCAACTGTTGGG \\
\hline \multirow{2}{*}{ adaptor DNA-I-40 } & \multirow{2}{*}{70} & TGCGGCTACTTCCCTTAGTGTGCGTGA-TTT- \\
\hline & & TATTACGCCAGCTGGCGAAAGGGGGATGTGCTGCAAGGCG \\
\hline \multirow{2}{*}{ adaptor DNA-I-41 } & \multirow{2}{*}{70} & TGCGGCTACTTCCCTTAGTGTGCGTGA-TTT- \\
\hline & & CCAGTCACGACGTTGTAAAACGACGGCCAGTGCCAAGCTT \\
\hline \multirow{2}{*}{ adaptor DNA-I-42 } & \multirow{2}{*}{70} & TGCGGCTACTTCCCTTAGTGTGCGTGA-TTT- \\
\hline & & TCCCCGGGTACCGAGCTCGAATTCGTAATCATGGTCATAG \\
\hline \multirow{2}{*}{ adaptor DNA-I-43 } & \multirow{2}{*}{70} & TGCGGCTACTTCCCTTAGTGTGCGTGA-TTT- \\
\hline & & СTCACAATTCCACACAACATACGAGCCGGAAGCATAAAGT \\
\hline \multirow{2}{*}{ adaptor DNA-I-44 } & \multirow{2}{*}{70} & TGCGGCTACTTCCCTTAGTGTGCGTGA-TTT- \\
\hline & & GCTAACTCACATTAATTGCGTTGCGCTCACTGCCCGCTTT \\
\hline \multirow{2}{*}{ adaptor DNA-I-45 } & \multirow{2}{*}{70} & TGCGGCTACTTCCCTTAGTGTGCGTGA-TTT- \\
\hline & & GCATTAATGAATCGGCCAACGCGCGGGGAGAGGCGGTTTG \\
\hline \multirow{2}{*}{ adaptor DNA-I-46 } & \multirow{2}{*}{70} & TGCGGCTACTTCCCTTAGTGTGCGTGA-TTT- \\
\hline & & TTTCACCAGTGAGACGGGCAACAGCTGATTGCCCTTCACC \\
\hline
\end{tabular}




\begin{tabular}{|c|c|c|}
\hline \multirow{2}{*}{ adaptor DNA-I-47 } & \multirow{2}{*}{70} & $\underline{\text { TGCGGCTACTTCCCTTAGTGTGCGTGA-TTT- }}$ \\
\hline & & CGGTCCACGCTGGTTTGCCCCAGCAGGCGAAAATCCTGTT \\
\hline \multirow{2}{*}{ adaptor DNA-I-48 } & \multirow{2}{*}{70} & TGCGGCTACTTCCCTTAGTGTGCGTGA-TTT- \\
\hline & & CCCTTATAAATCAAAAGAATAGCCCGAGATAGGGTTGAGT \\
\hline \multirow{2}{*}{ adaptor DNA-I-49 } & \multirow{2}{*}{70} & TGCGGCTACTTCCCTTAGTGTGCGTGA-TTT- \\
\hline & & CTATTAAAGAACGTGGACTCCAACGTCAAAGGGCGAAAAA \\
\hline \multirow{2}{*}{ adaptor DNA-I-50 } & \multirow{2}{*}{70} & IGCGGCTACTTCCCTTAGTGTGCGTGA-TTT- \\
\hline & & GTGAACCATCACCCAAATCAAGTTTTTTGGGGTCGAGGTG \\
\hline \multirow{2}{*}{ adaptor DNA-I-51 } & \multirow{2}{*}{70} & IGCGGCTACTTCCCTTAGTGTGCGTGA-TTT- \\
\hline & & AGGGAGCCCCCGATTTAGAGCTTGACGGGGAAAGCCGGCG \\
\hline \multirow{2}{*}{ adaptor DNA-I-52 } & \multirow{2}{*}{70} & IGCGGCTACTTCCCTTAGTGTGCGTGA-TTT- \\
\hline & & GCGAAAGGAGCGGGCGCTAGGGCGCTGGCAAGTGTAGCGG \\
\hline \multirow{2}{*}{ adaptor DNA-I-53 } & \multirow{2}{*}{70} & IGCGGCTACTTCCCTTAGTGTGCGTGA-TTT- \\
\hline & & CCGCGCTTAATGCGCCGCTACAGGGCGCGTACTATGGTTG \\
\hline \multirow{2}{*}{ adaptor DNA-I-54 } & \multirow{2}{*}{70} & TGCGGCTACTTCCCTTAGTGTGCGTGA-TTT- \\
\hline & & CCTCGTTAGAATCAGAGCGGGAGCTAAACAGGAGGCCGAT \\
\hline \multirow{2}{*}{ adaptor DNA-I-55 } & \multirow{2}{*}{70} & TGCGGCTACTTCCCTTAGTGTGCGTGA-TTT- \\
\hline & & GCCAGAATCCTGAGAAGTGTTTTTATAATCAGTGAGGCCA \\
\hline \multirow{2}{*}{ adaptor DNA-I-56 } & \multirow{2}{*}{70} & TGCGGCTACTTCCCTTAGTGTGCGTGA-TTT- \\
\hline & & AAATTAACCGTTGTAGCAATACTTCTTTGATTAGTAATAA \\
\hline \multirow{2}{*}{ adaptor DNA-I-57 } & \multirow{2}{*}{70} & TGCGGCTACTTCCCTTAGTGTGCGTGA-TTT- \\
\hline & & AACTATCGGCCTTGCTGGTAATATCCAGAACAATATTACC \\
\hline \multirow{2}{*}{ adaptor DNA-I-58 } & \multirow{2}{*}{70} & TGCGGCTACTTCCCTTAGTGTGCGTGA-TTT- \\
\hline & & CATGGAAATACCTACATTTTGACGCTCAATCGTCTGAAAT \\
\hline \multirow{2}{*}{ adaptor DNA-I-59 } & \multirow{2}{*}{70} & TGCGGCTACTTCCCTTAGTGTGCGTGA-TTT- \\
\hline & & GTCACACGACCAGTAATAAAAGGGACATTCTGGCCAACAG \\
\hline \multirow{2}{*}{ adaptor DNA-I-60 } & \multirow{2}{*}{70} & TGCGGCTACTTCCCTTAGTGTGCGTGA-TTT- \\
\hline & & TAAGAATACGTGGCACAGACAATATTTTTGAATGGCTATT \\
\hline \multirow{2}{*}{ adaptor DNA-I-61 } & \multirow{2}{*}{70} & TGCGGCTACTTCCCTTAGTGTGCGTGA-TTT- \\
\hline & & TAAAACATCGCCATTAAAAATACCGAACGAACCACCAGCA \\
\hline \multirow{2}{*}{ adaptor DNA-I-62 } & \multirow{2}{*}{70} & TGCGGCTACTTCCCTTAGTGTGCGTGA-TTT- \\
\hline & & GTATTAACACCGCCTGCAACAGTGCCACGCTGAGAGCCAG \\
\hline
\end{tabular}


adaptor DNA-I-63

adaptor DNA-I-64

adaptor DNA-I-65

adaptor DNA-I-66

adaptor DNA-I-67

adaptor DNA-I-68

adaptor DNA-I-69

adaptor DNA-I-70

adaptor DNA-I-71

adaptor DNA-I-72

adaptor DNA-I-73

adaptor DNA-I-74

adaptor DNA-I-75

adaptor DNA-I-76

adaptor DNA-I-77

adaptor DNA-I-78
TGCGGCTACTTCCCTTAGTGTGCGTGA-TTT -

CTTGCTGAACCTCAAATATCAAACCCTCAATCAATATCTG TGCGGCTACTTCCCTTAGTGTGCGTGA-TTTGAATTGAGGAAGGTTATCTAAAATATCTTTAGGAGCACTA TGCGGCTACTTCCCTTAGTGTGCGTGA-TTT GATAATACATTTGAGGATTTAGAAGTATTAGACTTTACAA TGCGGCTACTTCCCTTAGTGTGCGTGA-TTT TTGCCCGAACGTTATTAATTTTAAAAGTTTGAGTAACATT TGCGGCTACTTCCCTTAGTGTGCGTGA-TTT AGAAGGAGCGGAATTATCATCATATTCCTGATTATCAGAT TGCGGCTACTTCCCTTAGTGTGCGTGA-TTT TTGTTTGGATTATACTTCTGAATAATGGAAGGGTTAGAAC TGCGGCTACTTCCCTTAGTGTGCGTGA-TTTAAACAGAAATAAAGAAATTGCGTAGATTTTCAGGTTTAAC TGCGGCTACTTCCCTTAGTGTGCGTGA-TTT -

TTTTACATCGGGAGAAACAATAACGGATTCGCCTGATTGC TGCGGCTACTTCCCTTAGTGTGCGTGA-TTTAGAGGCGAATTATTCATTTCAATTACCTGAGCAAAAGAAG TGCGGCTACTTCCCTTAGTGTGCGTGA-TTTAATTAATTACATTTAACAATTTCATTTGAATTACCTTTTT TGCGGCTACTTCCCTTAGTGTGCGTGA-TTT ATGTGAGTGAATAACCTTGCTTCTGTAAATCGTCGCTATT TGCGGCTACTTCCCTTAGTGTGCGTGA-TTT AACATAGCGATAGCTTAGATTAAGACGCTGAGAAGAGTCA TGCGGCTACTTCCCTTAGTGTGCGTGA-TTTTGAGAGACTACCTTTTTAACCTCCGGCTTAGGTTGGGTTA TGCGGCTACTTCCCTTAGTGTGCGTGA-TTT ATCCAATCGCAAGACAAAGAACGCGAGAAAACTTTTTCAA TGCGGCTACTTCCCTTAGTGTGCGTGA-TTT ACCTAAATTTAATGGTTTGAAATACCGACCGTGTGATAAA TGCGGCTACTTCCCTTAGTGTGCGTGA-TTTGAATCATAATTACTAGAAAAAGCCTGTTTAGTATCATATG 


\begin{tabular}{|c|c|c|}
\hline \multirow{2}{*}{ adaptor DNA-I-79 } & \multirow{2}{*}{70} & TGCGGCTACTTCCCTTAGTGTGCGTGA-TTT- \\
\hline & & GCCAACGCTCAACAGTAGGGCTTAATTGAGAATCGCCATA \\
\hline \multirow{2}{*}{ adaptor DNA-I-80 } & \multirow{2}{*}{70} & TGCGGCTACTTCCCTTAGTGTGCGTGA-TTT- \\
\hline & & CAGAGGCATTTTCGAGCCAGTAATAAGAGAATATAAAGTA \\
\hline \multirow{2}{*}{ adaptor DNA-I-81 } & \multirow{2}{*}{70} & TGCGGCTACTTCCCTTAGTGTGCGTGA-TTT- \\
\hline & & AGACGACGACAATAAACAACATGTTCAGCTAATGCAGAAC \\
\hline \multirow{2}{*}{ adaptor DNA-I-82 } & \multirow{2}{*}{70} & TGCGGCTACTTCCCTTAGTGTGCGTGA-TTT- \\
\hline & & CCTGAACAAGAAAAATAATATCCCATCCTAATTTACGAGC \\
\hline \multirow{2}{*}{ adaptor DNA-I-83 } & \multirow{2}{*}{70} & TGCGGCTACTTCCCTTAGTGTGCGTGA-TTT- \\
\hline & & TCTTTCCTTATCATTCCAAGAACGGGTATTAAACCAAGTA \\
\hline \multirow{2}{*}{ adaptor DNA-I-84 } & \multirow{2}{*}{70} & TGCGGCTACTTCCCTTAGTGTGCGTGA-TTT- \\
\hline & & TTTTTATTTTCATCGTAGGAATCATTACCGCGCCCAATAG \\
\hline \multirow{2}{*}{ adaptor DNA-I-85 } & \multirow{2}{*}{70} & TGCGGCTACTTCCCTTAGTGTGCGTGA-TTT- \\
\hline & & CCGGTATTCTAAGAACGCGAGGCGTTTTAGCGAACCTCCC \\
\hline \multirow{2}{*}{ adaptor DNA-I-86 } & \multirow{2}{*}{70} & TGCGGCTACTTCCCTTAGTGTGCGTGA-TTT- \\
\hline & & ATCAAGATTAGTTGCTATTTTGCACCCAGCTACAATTTTA \\
\hline \multirow{2}{*}{ adaptor DNA-I-87 } & \multirow{2}{*}{70} & TGCGGCTACTTCCCTTAGTGTGCGTGA-TTT- \\
\hline & & GTCTTTCCAGAGCCTAATTTGCCAGTTACAAAATAAACAG \\
\hline \multirow{2}{*}{ adaptor DNA-I-88 } & \multirow{2}{*}{70} & TGCGGCTACTTCCCTTAGTGTGCGTGA-TTT- \\
\hline & & GAAACGATTTTTTGTTTAACGTCAAAAATGAAAATAGCAG \\
\hline \multirow{2}{*}{ adaptor DNA-I-89 } & \multirow{2}{*}{70} & TGCGGCTACTTCCCTTAGTGTGCGTGA-TTT- \\
\hline & & AGGGAAGCGCATTAGACGGGAGAATTAACTGAACACCCTG \\
\hline \multirow{2}{*}{ adaptor DNA-I-90 } & \multirow{2}{*}{70} & TGCGGCTACTTCCCTTAGTGTGCGTGA-TTT- \\
\hline & & AATATCAGAGAGATAACCCACAAGAATTGAGTTAAGCCCA \\
\hline \multirow{2}{*}{ adaptor DNA-I-91 } & \multirow{2}{*}{70} & TGCGGCTACTTCCCTTAGTGTGCGTGA-TTT- \\
\hline & & GCAATAGCTATCTTACCGAAGCCCTTTTTAAGAAAAGTAA \\
\hline \multirow{2}{*}{ adaptor DNA-I-92 } & \multirow{2}{*}{70} & TGCGGCTACTTCCCTTAGTGTGCGTGA-TTT- \\
\hline & & GGAAACCGAGGAAACGCAATAATAACGGAATACCCAAAAG \\
\hline \multirow{2}{*}{ adaptor DNA-I-93 } & \multirow{2}{*}{70} & TGCGGCTACTTCCCTTAGTGTGCGTGA-TTT- \\
\hline & & CGCAGTATGTTAGCAAACGTAGAAAATACATACATAAAGG \\
\hline \multirow{2}{*}{ adaptor DNA-I-94 } & \multirow{2}{*}{70} & TGCGGCTACTTCCCTTAGTGTGCGTGA-TTT- \\
\hline & & CACCACGGAATAAGTTTATTTTGTCACAATCAATAGAAAA \\
\hline
\end{tabular}




\begin{tabular}{|c|c|c|}
\hline \multirow{2}{*}{ adaptor DNA-I-95 } & \multirow{2}{*}{70} & TGCGGCTACTTCCCTTAGTGTGCGTGA-TTT- \\
\hline & & AAAAGGGCGACATTCAACCGATTGAGGGAGGGAAGGTAAA \\
\hline \multirow{2}{*}{ adaptor DNA-I-96 } & \multirow{2}{*}{70} & TGCGGCTACTTCCCTTAGTGTGCGTGA-TTT- \\
\hline & & GAATTATCACCGTCACCGACTTGAGCCATTTGGGAATTAG \\
\hline \multirow{2}{*}{ adaptor DNA-I-97 } & \multirow{2}{*}{70} & TGCGGCTACTTCCCTTAGTGTGCGTGA-TTT- \\
\hline & & TACCATTAGCAAGGCCGGAAACGTCACCAATGAAACCATC \\
\hline \multirow{2}{*}{ adaptor DNA-I-98 } & \multirow{2}{*}{70} & TGCGGCTACTTCCCTTAGTGTGCGTGA-TTT- \\
\hline & & AGAATCAAGTTTGCCTTTAGCGTCAGACTGTAGCGCGTTT \\
\hline \multirow{2}{*}{ adaptor DNA-I-99 } & \multirow{2}{*}{70} & TGCGGCTACTTCCCTTAGTGTGCGTGA-TTT- \\
\hline & & TTATTAGCGTTTGCCATCTTTTCATAATCAAAATCACCGG \\
\hline \multirow{2}{*}{ adaptor DNA-I-100 } & \multirow{2}{*}{70} & TGCGGCTACTTCCCTTAGTGTGCGTGA-TTT- \\
\hline & & CCTCAGAGCCGCCACCCTCAGAACCGCCACCCTCAGAGCC \\
\hline \multirow{2}{*}{ adaptor DNA-I-101 } & \multirow{2}{*}{70} & TGCGGCTACTTCCCTTAGTGTGCGTGA-TTT- \\
\hline & & ACCACCAGAGCCGCCGCCAGCATTGACAGGAGGTTGAGGC \\
\hline \multirow{2}{*}{ adaptor DNA-I-102 } & \multirow{2}{*}{70} & TGCGGCTACTTCCCTTAGTGTGCGTGA-TTT- \\
\hline & & CAAACAAATAAATCCTCATTAAAGCCAGAATGGAAAGCGC \\
\hline \multirow{2}{*}{ adaptor DNA-I-103 } & \multirow{2}{*}{70} & TGCGGCTACTTCCCTTAGTGTGCGTGA-TTT- \\
\hline & & CGTCATACATGGCTTTTGATGATACAGGAGTGTACTGGTA \\
\hline \multirow{2}{*}{ adaptor DNA-I-104 } & \multirow{2}{*}{70} & TGCGGCTACTTCCCTTAGTGTGCGTGA-TTT- \\
\hline & & AGTAACAGTGCCCGTATAAACAGTTAATGCCCCCTGCCTA \\
\hline \multirow{2}{*}{ adaptor DNA-I-105 } & \multirow{2}{*}{70} & TGCGGCTACTTCCCTTAGTGTGCGTGA-TTT- \\
\hline & & AAAGTATTAAGAGGCTGAGACTCCTCAAGAGAAGGATTAG \\
\hline \multirow{2}{*}{ adaptor DNA-I-106 } & \multirow{2}{*}{70} & TGCGGCTACTTCCCTTAGTGTGCGTGA-TTT- \\
\hline & & GCGGATAAGTGCCGTCGAGAGGGTTGATATAAGTATAGCC \\
\hline \multirow{2}{*}{ adaptor DNA-I-107 } & \multirow{2}{*}{70} & TGCGGCTACTTCCCTTAGTGTGCGTGA-TTT- \\
\hline & & AGGTTTAGTACCGCCACCCTCAGAACCGCCACCCTCAGAA \\
\hline \multirow{2}{*}{ adaptor DNA-I-108 } & \multirow{2}{*}{70} & TGCGGCTACTTCCCTTAGTGTGCGTGA-TTT- \\
\hline & & TTTTCAGGGATAGCAAGCCCAATAGGAACCCATGTACCGT \\
\hline
\end{tabular}


Table S3. Base Sequences of Adaptor DNA-II

\begin{tabular}{|c|c|c|}
\hline code & length (nt) & sequence $\left(5^{\prime}\right.$ to $\left.3^{\prime}\right)$ \\
\hline adaptor DNA-II-1 & 70 & $\begin{array}{l}\text { TACGAGAAAGTGATGTAGAACGGTGTA-TTT- } \\
\text { AGCATTCCACAGACAGCCCTCATAGTTAGCGTAACGATCT } \\
\text { The segments for the duplex formation with anchor DNA-II and } \\
\text { scaffold DNA are highlighted with underline and in red, } \\
\text { respectively. }\end{array}$ \\
\hline adaptor DNA-II-2 & 70 & $\begin{array}{l}\text { TACGAGAAAGTGATGTAGAACGGTGTA-TTT- } \\
\text { GTAAATGAATTTTCTGTATGGGATTTTGCTAAACAACTTT }\end{array}$ \\
\hline adaptor DNA-II-3 & 70 & $\begin{array}{l}\text { TACGAGAAAGTGATGTAGAACGGTGTA-TTT- } \\
\text { AAGGAACAACTAAAGGAATTGCGAATAATAATTTTTTCAC }\end{array}$ \\
\hline adaptor DNA-II-4 & 70 & $\begin{array}{l}\underline{\text { TACGAGAAAGTGATGTAGAACGGTGTA-TTT- }} \\
\text { AAAAGGAGCCTTTAATTGTATCGGTTTATCAGCTTGCTTT }\end{array}$ \\
\hline adaptor DNA-II-5 & 70 & $\begin{array}{l}\text { TACGAGAAAGTGATGTAGAACGGTGTA-TTA- } \\
\text { ACCGATAGTTGCGCCGACAATGACAACAACCATCGCCCAC }\end{array}$ \\
\hline adaptor DNA-II-6 & 70 & $\begin{array}{l}\text { TACGAGAAAGTGATGTAGAACGGTGTA-TTT - } \\
\text { GCTTGCAGGGAGTTAAAGGCCGCTTTTGCGGGATCGTCAC }\end{array}$ \\
\hline adaptor DNA-II-7 & 70 & $\begin{array}{l}\text { TACGAGAAAGTGATGTAGAACGGTGTA-TTT - } \\
\text { CGAGGGTAGCAACGGCTACAGAGGCTTTGAGGACTAAAGA }\end{array}$ \\
\hline adaptor DNA-II-8 & 70 & $\begin{array}{l}\text { TACGAGAAAGTGATGTAGAACGGTGTA-TTT - } \\
\text { CGGGTAAAATACGTAATGCCACTACGAAGGCACCAACCTA }\end{array}$ \\
\hline adaptor DNA-II-9 & 70 & $\begin{array}{l}\text { TACGAGAAAGTGATGTAGAACGGTGTA-TTT - } \\
\text { AAACACTCATCTTTGACCCCCAGCGATTATACCAAGCGCG }\end{array}$ \\
\hline adaptor DNA-II-10 & 70 & $\begin{array}{l}\text { TACGAGAAAGTGATGTAGAACGGTGTA-TTT - } \\
\text { ATCGCCTGATAAATTGTGTCGAAATCCGCGACCTGCTCCA }\end{array}$ \\
\hline adaptor DNA-II-11 & 70 & $\begin{array}{l}\text { TACGAGAAAGTGATGTAGAACGGTGTA-TTT - } \\
\text { CGGTCAATCATAAGGGAACCGAACTGACCAACTTTGAAAG }\end{array}$ \\
\hline adaptor DNA-II-12 & 70 & $\begin{array}{l}\text { TACGAGAAAGTGATGTAGAACGGTGTA-TTT- } \\
\text { GCGCATAGGCTGGCTGACCTTCATCAAGAGTAATCTTGAC }\end{array}$ \\
\hline adaptor DNA-II-13 & 70 & $\begin{array}{l}\text { TACGAGAAAGTGATGTAGAACGGTGTA-TTT- } \\
\text { AACGTAACAAAGCTGCTCATTCAGTGAATAAGGCTTGCCC }\end{array}$ \\
\hline adaptor DNA-II-14 & 70 & $\begin{array}{l}\text { TACGAGAAAGTGATGTAGAACGGTGTA-TTT - } \\
\text { AATTGGGCTTGAGATGGTTTAATTTCAACTTTAATCATTG }\end{array}$ \\
\hline
\end{tabular}




\begin{tabular}{|c|c|c|}
\hline \multirow{2}{*}{ adaptor DNA-II-15 } & \multirow{2}{*}{70} & $\underline{\text { TACGAGAAAGTGATGTAGAACGGTGTA-TTT- }}$ \\
\hline & & TGGCTCATTATACCAGTCAGGACGTTGGGAAGAAAAATCT \\
\hline \multirow{2}{*}{ adaptor DNA-II-16 } & \multirow{2}{*}{70} & TACGAGAAAGTGATGTAGAACGGTGTA-TTT- \\
\hline & & ACATTATTACAGGTAGAAAGATTCATCAGTTGAGATTTAG \\
\hline \multirow{2}{*}{ adaptor DNA-II-17 } & \multirow{2}{*}{70} & IACGAGAAAGTGATGTAGAACGGTGTA-TTT- \\
\hline & & CATAACGCCAAAAGGAATTACGAGGCATAGTAAGAGCAAC \\
\hline \multirow{2}{*}{ adaptor DNA-II-18 } & \multirow{2}{*}{70} & $\underline{\text { TACGAGAAAGTGATGTAGAACGGTGTA-TTT - }}$ \\
\hline & & ACGATAAAAACCAAAATAGCGAGAGGCTTTTGCAAAAGAA \\
\hline \multirow{2}{*}{ adaptor DNA-II-19 } & \multirow{2}{*}{70} & $\underline{\text { TACGAGAAAGTGATGTAGAACGGTGTA-TTT - }}$ \\
\hline & & TGTTTAGACTGGATAGCGTCCAATACTGCGGAATCGTCAT \\
\hline \multirow{2}{*}{ adaptor DNA-II-20 } & \multirow{2}{*}{70} & $\underline{\text { TACGAGAAAGTGATGTAGAACGGTGTA-TTT- }}$ \\
\hline & & CTTTAAACAGTTCAGAAAACGAGAATGACCATAAATCAAA \\
\hline \multirow{2}{*}{ adaptor DNA-II-21 } & \multirow{2}{*}{70} & $\underline{\text { TACGAGAAAGTGATGTAGAACGGTGTA-TTT- }}$ \\
\hline & & GTCAGAAGCAAAGCGGATTGCATCAAAAAGATTAAGAGGA \\
\hline \multirow{2}{*}{ adaptor DNA-II-22 } & \multirow{2}{*}{70} & TACGAGAAAGTGATGTAGAACGGTGTA-TTT- \\
\hline & & TTAATTCGAGCTTCAAAGCGAACCAGACCGGAAGCAAACT \\
\hline \multirow{2}{*}{ adaptor DNA-II-23 } & \multirow{2}{*}{70} & $\underline{\text { TACGAGAAAGTGATGTAGAACGGTGTA-TTT- }}$ \\
\hline & & TTAATTGCTCCTTTTGATAAGAGGTCATTTTTGCGGATGG \\
\hline \multirow{2}{*}{ adaptor DNA-II-24 } & \multirow{2}{*}{70} & $\underline{\text { TACGAGAAAGTGATGTAGAACGGTGTA-TTT- }}$ \\
\hline & & CTGTAGCTCAACATGTTTTAAATATGCAACTAAAGTACGG \\
\hline \multirow{2}{*}{ adaptor DNA-II-25 } & \multirow{2}{*}{70} & TACGAGAAAGTGATGTAGAACGGTGTA-TTT - \\
\hline & & GTTGATTCCCAATTCTGCGAACGAGTAGATTTAGTTTGAC \\
\hline \multirow{2}{*}{ adaptor DNA-II-26 } & \multirow{2}{*}{70} & TACGAGAAAGTGATGTAGAACGGTGTA-TTT - \\
\hline & & TAACCTGTTTAGCTATATTTTCATTTGGGGCGCGAGCTGA \\
\hline \multirow{2}{*}{ adaptor DNA-II-27 } & \multirow{2}{*}{70} & TACGAGAAAGTGATGTAGAACGGTGTA-TTT- \\
\hline & & AGTAGCATTAACATCCAATAAATCATACAGGCAAGGCAAA \\
\hline \multirow{2}{*}{ adaptor DNA-II-28 } & \multirow{2}{*}{70} & $\underline{\text { TACGAGAAAGTGATGTAGAACGGTGTA-TTT - }}$ \\
\hline & & TCAGAGCATAAAGCTAAATCGGTTGTACCAAAAACATTAT \\
\hline \multirow{2}{*}{ adaptor DNA-II-29 } & \multirow{2}{*}{70} & $\underline{\text { TACGAGAAAGTGATGTAGAACGGTGTA-TTT - }}$ \\
\hline & & СCTTTATTTCAACGCAAGGATAAAAATTTTTAAGAACCCTC \\
\hline \multirow{2}{*}{ adaptor DNA-II-30 } & \multirow{2}{*}{70} & $\underline{\text { TACGAGAAAGTGATGTAGAACGGTGTA-TTT - }}$ \\
\hline & & ATGTGTAGGTAAAGATTCAAAAGGGTGAGAAAGGCCGGAG \\
\hline
\end{tabular}




\begin{tabular}{|c|c|c|}
\hline adaptor DNA-II-31 & 70 & $\begin{array}{l}\text { TACGAGAAAGTGATGTAGAACGGTGTA-TTT- } \\
\text { TCAACCGTTCTAGCTGATAAATTAATGCCGGAGAGGGTAG }\end{array}$ \\
\hline \multirow{2}{*}{ adaptor DNA-II-32 } & \multirow{2}{*}{70} & $\underline{\text { TACGAGAAAGTGATGTAGAACGGTGTA-TTT - }}$ \\
\hline & & TCAGGTCATTGCCTGAGAGTCTGGAGCAAACAAGAGAATC \\
\hline \multirow{2}{*}{ adaptor DNA-II-33 } & \multirow{2}{*}{70} & $\underline{\text { TACGAGAAAGTGATGTAGAACGGTGTA-TTT- }}$ \\
\hline & & GTCAATCATATGTACCCCGGTTGATAATCAGAAAAGCCCC \\
\hline \multirow{2}{*}{ adaptor DNA-II-34 } & \multirow{2}{*}{70} & TACGAGAAAGTGATGTAGAACGGTGTA-TTT- \\
\hline & & ATTTAAATTGTAAACGTTAATATTTTGTTAAAATTCGCAT \\
\hline \multirow{2}{*}{ adaptor DNA-II-35 } & \multirow{2}{*}{70} & $\underline{\text { TACGAGAAAGTGATGTAGAACGGTGTA-TTT- }}$ \\
\hline & & TTAACCAATAGGAACGCCATCAAAAATAATTCGCGTCTGG \\
\hline \multirow{2}{*}{ adaptor DNA-II-36 } & \multirow{2}{*}{70} & TACGAGAAAGTGATGTAGAACGGTGTA-TTT- \\
\hline & & TTAAATGTGAGCGAGTAACAACCCGTCGGATTCTCCGTGG \\
\hline \multirow{2}{*}{ adaptor DNA-II-37 } & \multirow{2}{*}{70} & $\underline{\text { TACGAGAAAGTGATGTAGAACGGTGTA-TTT - }}$ \\
\hline & & GATAGGTCACGTTGGTGTAGATGGGCGCATCGTAACCGTG \\
\hline \multirow{2}{*}{ adaptor DNA-II-38 } & \multirow{2}{*}{70} & $\underline{\text { TACGAGAAAGTGATGTAGAACGGTGTA-TTT - }}$ \\
\hline & & AGTATCGGCCTCAGGAAGATCGCACTCCAGCCAGCTTTCC \\
\hline \multirow{2}{*}{ adaptor DNA-II-39 } & \multirow{2}{*}{70} & $\underline{\text { TACGAGAAAGTGATGTAGAACGGTGTA-TTT- }}$ \\
\hline & & GCAAAGCGCCATTCGCCATTCAGGCTGCGCAACTGTTGGG \\
\hline \multirow{2}{*}{ adaptor DNA-II-40 } & \multirow{2}{*}{70} & $\underline{\text { TACGAGAAAGTGATGTAGAACGGTGTA-TTT- }}$ \\
\hline & & TATTACGCCAGCTGGCGAAAGGGGGATGTGCTGCAAGGCG \\
\hline \multirow{2}{*}{ adaptor DNA-II-41 } & \multirow{2}{*}{70} & $\underline{\text { TACGAGAAAGTGATGTAGAACGGTGTA-TTT- }}$ \\
\hline & & CCAGTCACGACGTTGTAAAACGACGGCCAGTGCCAAGCTT \\
\hline \multirow{2}{*}{ adaptor DNA-II-42 } & \multirow{2}{*}{70} & $\underline{\text { TACGAGAAAGTGATGTAGAACGGTGTA-TTT- }}$ \\
\hline & & TCCCCGGGTACCGAGCTCGAATTCGTAATCATGGTCATAG \\
\hline \multirow{2}{*}{ adaptor DNA-II-43 } & \multirow{2}{*}{70} & $\underline{\underline{\text { TACGAGAAAGTGATGTAGAACGGTGTA-TTT- }}}$ \\
\hline & & CTCACAATTCCACACAACATACGAGCCGGAAGCATAAAGT \\
\hline \multirow{2}{*}{ adaptor DNA-II-44 } & \multirow{2}{*}{70} & $\underline{\text { TACGAGAAAGTGATGTAGAACGGTGTA-TTT- }}$ \\
\hline & & GCTAACTCACATTAATTGCGTTGCGCTCACTGCCCGCTTT \\
\hline \multirow{2}{*}{ adaptor DNA-II-45 } & \multirow{2}{*}{70} & $\underline{\text { TACGAGAAAGTGATGTAGAACGGTGTA-TTT - }}$ \\
\hline & & GCATTAATGAATCGGCCAACGCGCGGGGAGAGGCGGTTTG \\
\hline \multirow{2}{*}{ adaptor DNA-II-46 } & \multirow{2}{*}{70} & TACGAGAAAGTGATGTAGAACGGTGTA-TTT- \\
\hline & & TTTCACCAGTGAGACGGGCAACAGCTGATTGCCCTTCACC \\
\hline
\end{tabular}




\begin{tabular}{|c|c|c|}
\hline adaptor DNA-II-47 & 70 & $\begin{array}{l}\text { TACGAGAAAGTGATGTAGAACGGTGTA-TTT- } \\
\text { CGGTCCACGCTGGTTTGCCCCAGCAGGCGAAAATCCTGTT }\end{array}$ \\
\hline adaptor DNA-II-48 & 70 & $\begin{array}{l}\text { TACGAGAAAGTGATGTAGAACGGTGTA-TTT- } \\
\text { CCCTTATAAATCAAAAGAATAGCCCGAGATAGGGTTGAGT }\end{array}$ \\
\hline adaptor DNA-II-49 & 70 & $\begin{array}{l}\text { TACGAGAAAGTGATGTAGAACGGTGTA-TTT- } \\
\text { CTATTAAAGAACGTGGACTCCAACGTCAAAGGGCGAAAAA }\end{array}$ \\
\hline adaptor DNA-II-50 & 70 & $\begin{array}{l}\text { TACGAGAAAGTGATGTAGAACGGTGTA-TTT- } \\
\text { GTGAACCATCACCCAAATCAAGTTTTTTGGGGTCGAGGTG }\end{array}$ \\
\hline adaptor DNA-II-51 & 70 & $\begin{array}{l}\underline{\text { TACGAGAAAGTGATGTAGAACGGTGTA-TTT- }} \\
\text { AGGGAGCCCCCGATTTAGAGCTTGACGGGGAAAGCCGGCG }\end{array}$ \\
\hline adaptor DNA-II-52 & 70 & $\begin{array}{l}\underline{\text { TACGAGAAAGTGATGTAGAACGGTGTA-TTT- }} \\
\text { GCGAAAGGAGCGGGCGCTAGGGCGCTGGCAAGTGTAGCGG }\end{array}$ \\
\hline adaptor DNA-II-53 & 70 & $\begin{array}{l}\underline{\text { TACGAGAAAGTGATGTAGAACGGTGTA-TTT- }} \\
\text { CCGCGCTTAATGCGCCGCTACAGGGCGCGTACTATGGTTG }\end{array}$ \\
\hline adaptor DNA-II-54 & 70 & $\begin{array}{l}\underline{\text { TACGAGAAAGTGATGTAGAACGGTGTA-TTT- }} \\
\text { CCTCGTTAGAATCAGAGCGGGAGCTAAACAGGAGGCCGAT }\end{array}$ \\
\hline adaptor DNA-II-55 & 70 & $\begin{array}{l}\underline{\text { TACGAGAAAGTGATGTAGAACGGTGTA-TTT- }} \\
\text { GCCAGAATCCTGAGAAGTGTTTTTATAATCAGTGAGGCCA }\end{array}$ \\
\hline adaptor DNA-II-56 & 70 & $\begin{array}{l}\text { TACGAGAAAGTGATGTAGAACGGTGTA-TTT- } \\
\text { AAATTAACCGTTGTAGCAATACTTCTTTGATTAGTAATAA }\end{array}$ \\
\hline adaptor DNA-II-57 & 70 & $\begin{array}{l}\text { TACGAGAAAGTGATGTAGAACGGTGTA-TTT- } \\
\text { AACTATCGGCCTTGCTGGTAATATCCAGAACAATATTACC }\end{array}$ \\
\hline adaptor DNA-II-58 & 70 & $\begin{array}{l}\text { TACGAGAAAGTGATGTAGAACGGTGTA-TTT- } \\
\text { CATGGAAATACCTACATTTTGACGCTCAATCGTCTGAAAT }\end{array}$ \\
\hline adaptor DNA-II-59 & 70 & $\begin{array}{l}\text { TACGAGAAAGTGATGTAGAACGGTGTA-TTT- } \\
\text { GTCACACGACCAGTAATAAAAGGGACATTCTGGCCAACAG }\end{array}$ \\
\hline adaptor DNA-II-60 & 70 & $\begin{array}{l}\text { TACGAGAAAGTGATGTAGAACGGTGTA-TTT- } \\
\text { TAAGAATACGTGGCACAGACAATATTTTTGAATGGCTATT }\end{array}$ \\
\hline adaptor DNA-II-61 & 70 & $\begin{array}{l}\text { TACGAGAAAGTGATGTAGAACGGTGTA-TTT- } \\
\text { TAAAACATCGCCATTAAAAATACCGAACGAACCACCAGCA }\end{array}$ \\
\hline adaptor DNA-II-62 & 70 & $\begin{array}{l}\text { TACGAGAAAGTGATGTAGAACGGTGTA-TTT- } \\
\text { GTATTAACACCGCCTGCAACAGTGCCACGCTGAGAGCCAG }\end{array}$ \\
\hline
\end{tabular}


adaptor DNA-II-63

adaptor DNA-II-64

adaptor DNA-II-65

adaptor DNA-II-66

adaptor DNA-II-67

adaptor DNA-II-68

adaptor DNA-II-69

adaptor DNA-II-70

adaptor DNA-II-71

adaptor DNA-II-72

adaptor DNA-II-73

adaptor DNA-II-74

adaptor DNA-II-75

adaptor DNA-II-76

adaptor DNA-II-77

adaptor DNA-II-78
70

70

70

70

70

70

70

70

70

70

70

70

70

70

70

70
TACGAGAAAGTGATGTAGAACGGTGTA-TTTCTTGCTGAACCTCAAATATCAAACCCTCAATCAATATCTG TACGAGAAAGTGATGTAGAACGGTGTA-TTT GAATTGAGGAAGGTTATCTAAAATATCTTTAGGAGCACTA TACGAGAAAGTGATGTAGAACGGTGTA-TTT -

GATAATACATTTGAGGATTTAGAAGTATTAGACTTTACAA

TACGAGAAAGTGATGTAGAACGGTGTA-TTT -

TTGCCCGAACGTTATTAATTTTAAAAGTTTGAGTAACATT

TACGAGAAAGTGATGTAGAACGGTGTA-TTTAGAAGGAGCGGAATTATCATCATATTCCTGATTATCAGAT

TACGAGAAAGTGATGTAGAACGGTGTA-TTT-

TTGTTTGGATTATACTTCTGAATAATGGAAGGGTTAGAAC TACGAGAAAGTGATGTAGAACGGTGTA-TTT -

AAACAGAAATAAAGAAATTGCGTAGATTTTCAGGTTTAAC TACGAGAAAGTGATGTAGAACGGTGTA-TTT-

TTTTACATCGGGAGAAACAATAACGGATTCGCCTGATTGC TACGAGAAAGTGATGTAGAACGGTGTA-TTTAGAGGCGAATTATTCATTTCAATTACCTGAGCAAAAGAAG TACGAGAAAGTGATGTAGAACGGTGTA-TTT AATTAATTACATTTAACAATTTCATTTGAATTACCTTTTT TACGAGAAAGTGATGTAGAACGGTGTA-TTT ATGTGAGTGAATAACCTTGCTTCTGTAAATCGTCGCTATT TACGAGAAAGTGATGTAGAACGGTGTA-TTT-

AACATAGCGATAGCTTAGATTAAGACGCTGAGAAGAGTCA TACGAGAAAGTGATGTAGAACGGTGTA-TTT -

TGAGAGACTACCTTTTTAACCTCCGGCTTAGGTTGGGTTA TACGAGAAAGTGATGTAGAACGGTGTA-TTT ATCCAATCGCAAGACAAAGAACGCGAGAAAACTTTTTCAA TACGAGAAAGTGATGTAGAACGGTGTA-TTT ACCTAAATTTAATGGTTTGAAATACCGACCGTGTGATAAA TACGAGAAAGTGATGTAGAACGGTGTA-TTTGAATCATAATTACTAGAAAAAGCCTGTTTAGTATCATATG 


\begin{tabular}{|c|c|c|}
\hline adaptor DNA-II-79 & 70 & $\begin{array}{l}\text { TACGAGAAAGTGATGTAGAACGGTGTA-TTT- } \\
\text { GCCAACGCTCAACAGTAGGGCTTAATTGAGAATCGCCATA }\end{array}$ \\
\hline adaptor DNA-II-80 & 70 & $\begin{array}{l}\text { TACGAGAAAGTGATGTAGAACGGTGTA-TTT- } \\
\text { CAGAGGCATTTTCGAGCCAGTAATAAGAGAATATAAAGTA }\end{array}$ \\
\hline adaptor DNA-II-81 & 70 & $\begin{array}{l}\text { TACGAGAAAGTGATGTAGAACGGTGTA-TTT- } \\
\text { AGACGACGACAATAAACAACATGTTCAGCTAATGCAGAAC }\end{array}$ \\
\hline adaptor DNA-II-82 & 70 & $\begin{array}{l}\text { TACGAGAAAGTGATGTAGAACGGTGTA-TTT- } \\
\text { CCTGAACAAGAAAAATAATATCCCATCCTAATTTACGAGC }\end{array}$ \\
\hline adaptor DNA-II-83 & 70 & $\begin{array}{l}\underline{\text { TACGAGAAAGTGATGTAGAACGGTGTA-TTT- }} \\
\text { TCTTTCCTTATCATTCCAAGAACGGGTATTAAACCAAGTA }\end{array}$ \\
\hline adaptor DNA-II-84 & 70 & $\begin{array}{l}\underline{\text { TACGAGAAAGTGATGTAGAACGGTGTA-TTT- }} \\
\text { TTTTTATTTTCATCGTAGGAATCATTACCGCGCCCAATAG }\end{array}$ \\
\hline adaptor DNA-II-85 & 70 & $\begin{array}{l}\text { TACGAGAAAGTGATGTAGAACGGTGTA-TTT- } \\
\text { CCGGTATTCTAAGAACGCGAGGCGTTTTAGCGAACCTCCC }\end{array}$ \\
\hline adaptor DNA-II-86 & 70 & $\begin{array}{l}\underline{\text { TACGAGAAAGTGATGTAGAACGGTGTA-TTT- }} \\
\text { ATCAAGATTAGTTGCTATTTTGCACCCAGCTACAATTTTA }\end{array}$ \\
\hline adaptor DNA-II-87 & 70 & $\begin{array}{l}\text { TACGAGAAAGTGATGTAGAACGGTGTA-TTT- } \\
\text { GTCTTTCCAGAGCCTAATTTGCCAGTTACAAAATAAACAG }\end{array}$ \\
\hline adaptor DNA-II-88 & 70 & $\begin{array}{l}\text { TACGAGAAAGTGATGTAGAACGGTGTA-TTT- } \\
\text { GAAACGATTTTTTGTTTAACGTCAAAAATGAAAATAGCAG }\end{array}$ \\
\hline adaptor DNA-II-89 & 70 & $\begin{array}{l}\text { TACGAGAAAGTGATGTAGAACGGTGTA-TTT- } \\
\text { AGGGAAGCGCATTAGACGGGAGAATTAACTGAACACCCTG }\end{array}$ \\
\hline adaptor DNA-II-90 & 70 & $\begin{array}{l}\underline{\text { TACGAGAAAGTGATGTAGAACGGTGTA-TTT- }} \\
\text { AATATCAGAGAGATAACCCACAAGAATTGAGTTAAGCCCA }\end{array}$ \\
\hline adaptor DNA-II-91 & 70 & $\begin{array}{l}\underline{\text { TACGAGAAAGTGATGTAGAACGGTGTA-TTT- }} \\
\text { GCAATAGCTATCTTACCGAAGCCCTTTTTAAGAAAAGTAA }\end{array}$ \\
\hline adaptor DNA-II-92 & 70 & $\begin{array}{l}\underline{\text { TACGAGAAAGTGATGTAGAACGGTGTA-TTT- }} \\
\text { GGAAACCGAGGAAACGCAATAATAACGGAATACCCAAAAG }\end{array}$ \\
\hline adaptor DNA-II-93 & 70 & $\begin{array}{l}\underline{\text { TACGAGAAAGTGATGTAGAACGGTGTA-TTT- }} \\
\text { CGCAGTATGTTAGCAAACGTAGAAAATACATACATAAAGG }\end{array}$ \\
\hline adaptor DNA-II-94 & 70 & $\begin{array}{l}\text { TACGAGAAAGTGATGTAGAACGGTGTA-TTT- } \\
\text { CACCACGGAATAAGTTTATTTTGTCACAATCAATAGAAAA }\end{array}$ \\
\hline
\end{tabular}


adaptor DNA-II-95

adaptor DNA-II-96

adaptor DNA-II-97

adaptor DNA-II-98

adaptor DNA-II-99

adaptor DNA-II-100

adaptor DNA-II-101

adaptor DNA-II-102

adaptor DNA-II-103

adaptor DNA-II-104

adaptor DNA-II-105

adaptor DNA-II-106

adaptor DNA-II-107

adaptor DNA-II-108
70

70

70

70

70

70

70

70

70

70

70

70

70

70
TACGAGAAAGTGATGTAGAACGGTGTA-TTT AAAAGGGCGACATTCAACCGATTGAGGGAGGGAAGGTAAA TACGAGAAAGTGATGTAGAACGGTGTA-TTTGAATTATCACCGTCACCGACTTGAGCCATTTGGGAATTAG TACGAGAAAGTGATGTAGAACGGTGTA-TTTTACCATTAGCAAGGCCGGAAACGTCACCAATGAAACCATC TACGAGAAAGTGATGTAGAACGGTGTA-TTT AGAATCAAGTTTGCCTTTAGCGTCAGACTGTAGCGCGTTT TACGAGAAAGTGATGTAGAACGGTGTA-TTT TTATTAGCGTTTGCCATCTTTTCATAATCAAAATCACCGG TACGAGAAAGTGATGTAGAACGGTGTA-TTTCCTCAGAGCCGCCACCCTCAGAACCGCCACCCTCAGAGCC TACGAGAAAGTGATGTAGAACGGTGTA-TTT ACCACCAGAGCCGCCGCCAGCATTGACAGGAGGTTGAGGC TACGAGAAAGTGATGTAGAACGGTGTA-TTT CAAACAAATAAATCCTCATTAAAGCCAGAATGGAAAGCGC TACGAGAAAGTGATGTAGAACGGTGTA-TTTCGTCATACATGGCTTTTGATGATACAGGAGTGTACTGGTA TACGAGAAAGTGATGTAGAACGGTGTA-TTT AGTAACAGTGCCCGTATAAACAGTTAATGCCCCCTGCCTA TACGAGAAAGTGATGTAGAACGGTGTA-TTT AAAGTATTAAGAGGCTGAGACTCCTCAAGAGAAGGATTAG TACGAGAAAGTGATGTAGAACGGTGTA-TTT GCGGATAAGTGCCGTCGAGAGGGTTGATATAAGTATAGCC TACGAGAAAGTGATGTAGAACGGTGTA-TTT AGGTTTAGTACCGCCACCCTCAGAACCGCCACCCTCAGAA TACGAGAAAGTGATGTAGAACGGTGTA-TTT TTTTCAGGGATAGCAAGCCCAATAGGAACCCATGTACCGT 
Table S4. Composition of Template DNA

\begin{tabular}{cccc} 
code & scaffold DNA & adaptor DNA-I & adaptor DNA-II \\
template DNA-1 & Used & $\# 1-108$ & Not used \\
template DNA-2 & Used & Not used & $\# 1-108$ \\
template DNA-3 & Used & All odd numbers & All even numbers \\
& $(\# 1,3, \ldots 105,107)$ & $(\# 2,4, \ldots 106,108)$ \\
template DNA-4 & Used & $\# 1-54$ & $\# 55-108$ \\
\hline
\end{tabular}




\section{S-3. ADDITIONAL FIGURES}
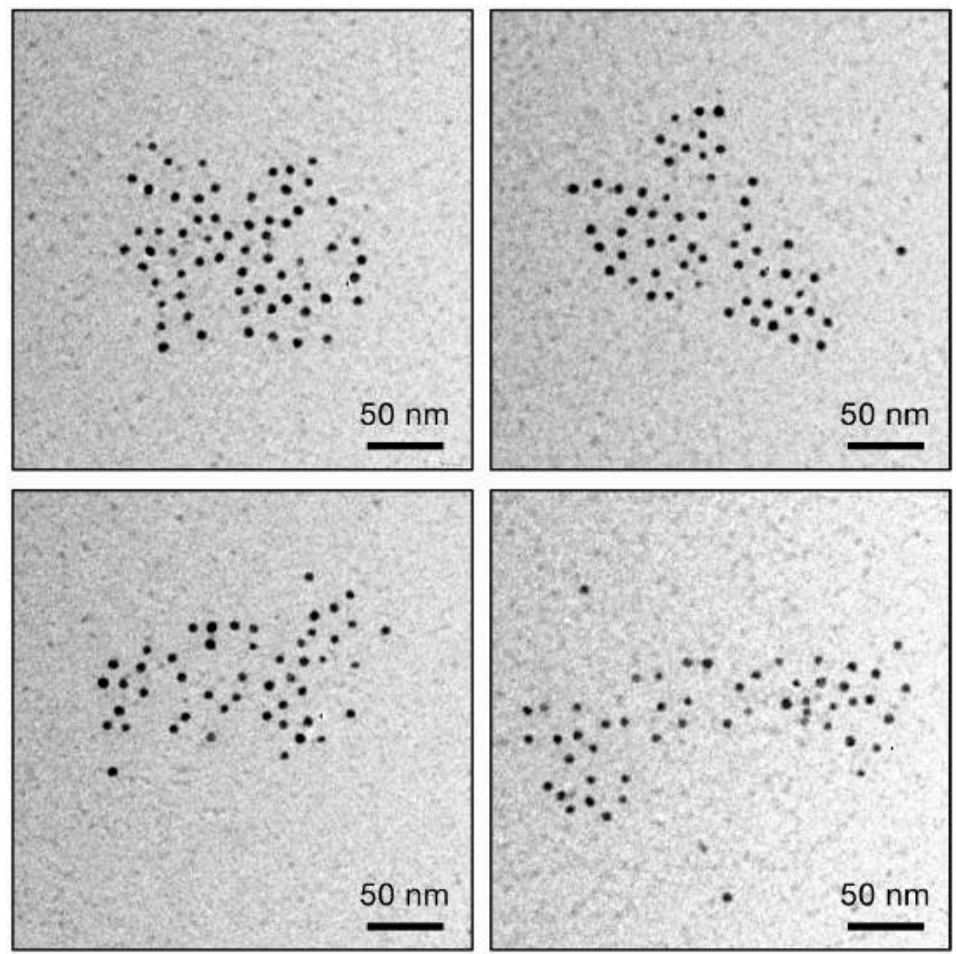

Figure S1. Additional TEM images for the homo-assembly of ssDNA-AuNPs with a diameter of $5 \mathrm{~nm}$. 


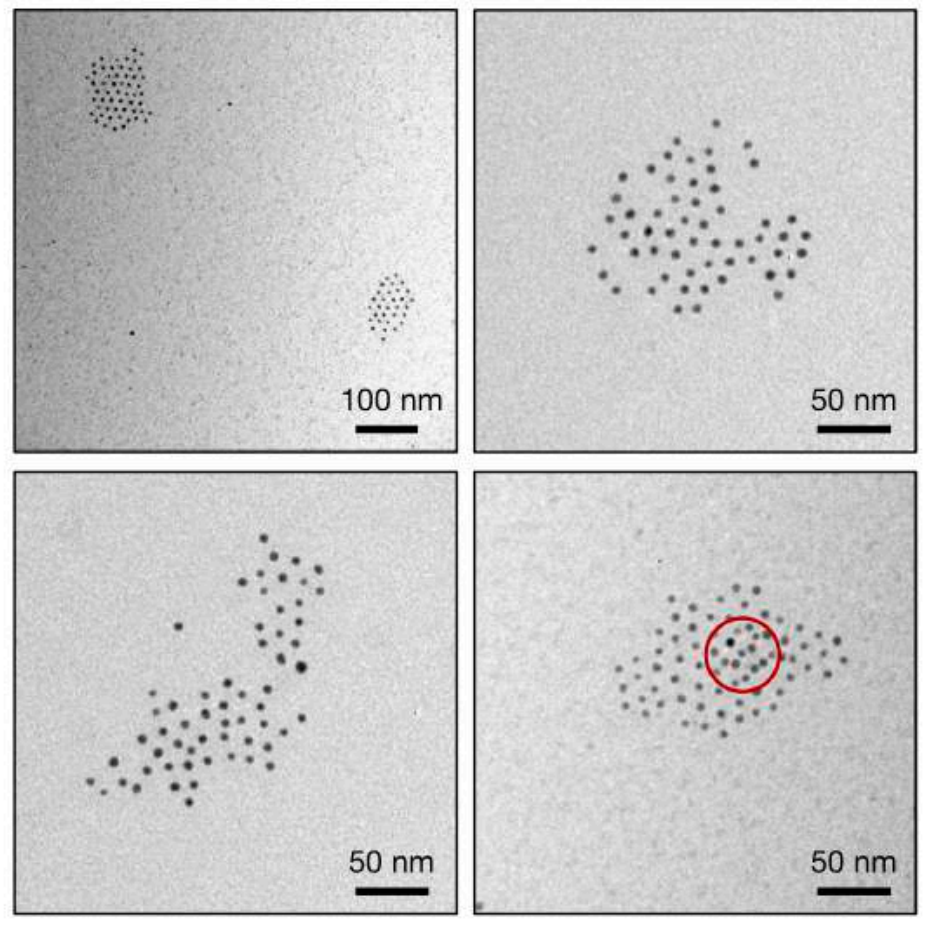

Figure S2. Additional TEM images for the homo-assembly of fully matched dsDNA-AuNPs with a diameter of $5 \mathrm{~nm}$. The red circle indicates the multilayer structure. 


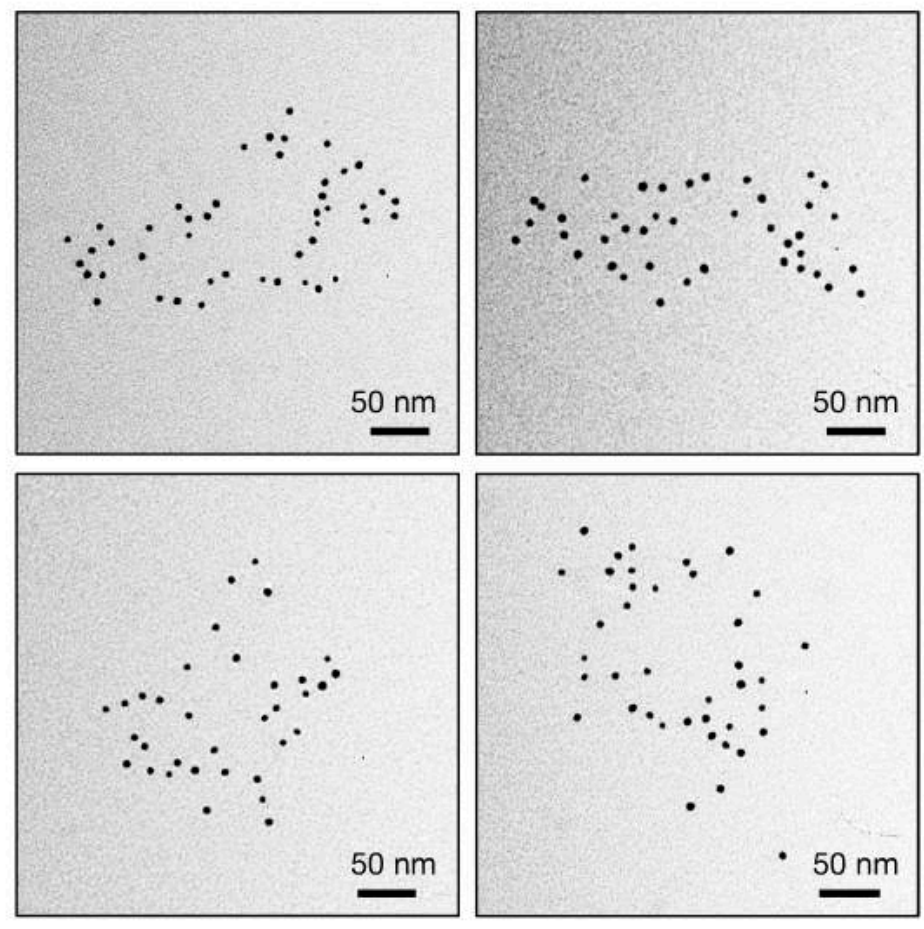

Figure S3. Additional TEM images for the homo-assembly of terminal-mismatched dsDNAAuNPs with a diameter of $5 \mathrm{~nm}$. 


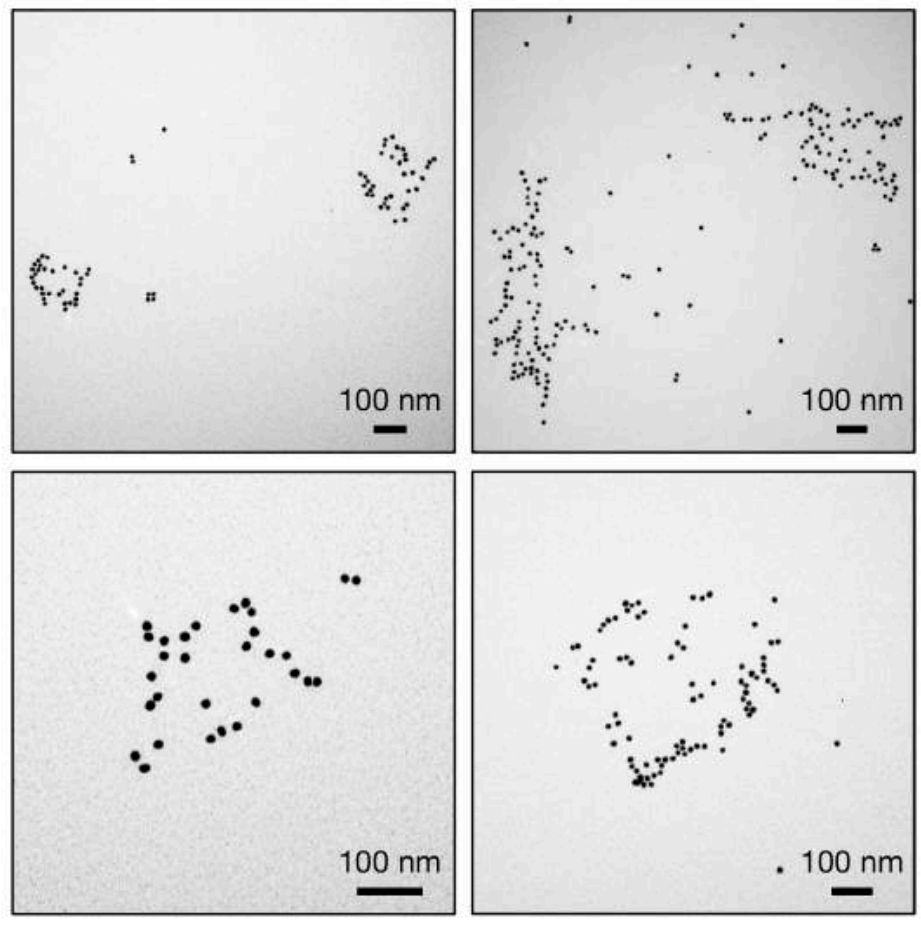

Figure S4. Additional TEM images for the homo-assembly of ssDNA-AuNPs with a diameter of $15 \mathrm{~nm}$. 

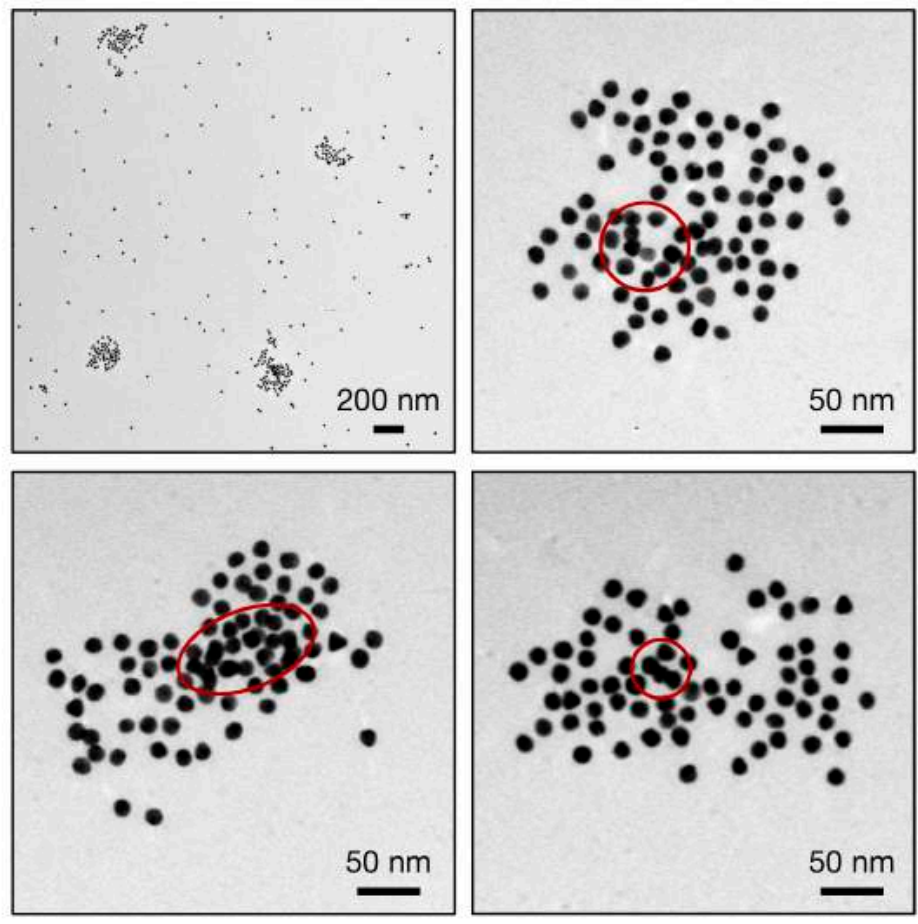

Figure S5. Additional TEM images for the homo-assembly of fully matched dsDNA-AuNPs with a diameter of $15 \mathrm{~nm}$. The red circles indicate the multilayer structure. 


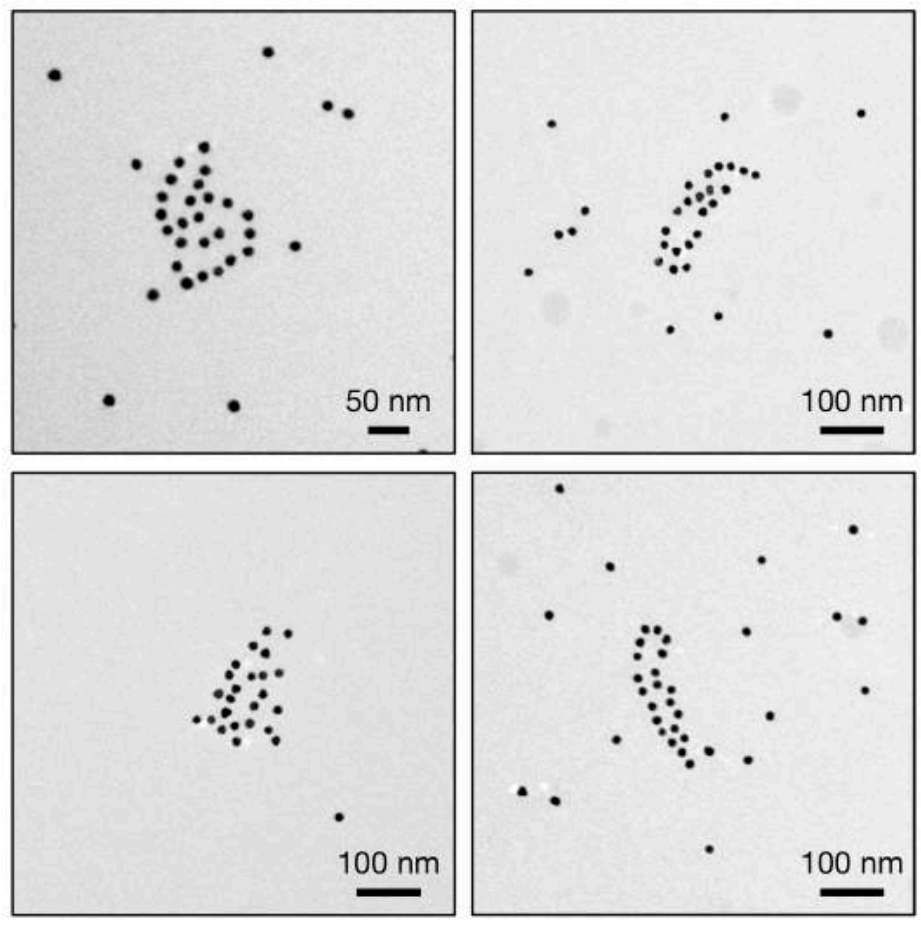

Figure S6. Additional TEM images for the homo-assembly of terminal-mismatched dsDNAAuNPs with a diameter of $15 \mathrm{~nm}$. 


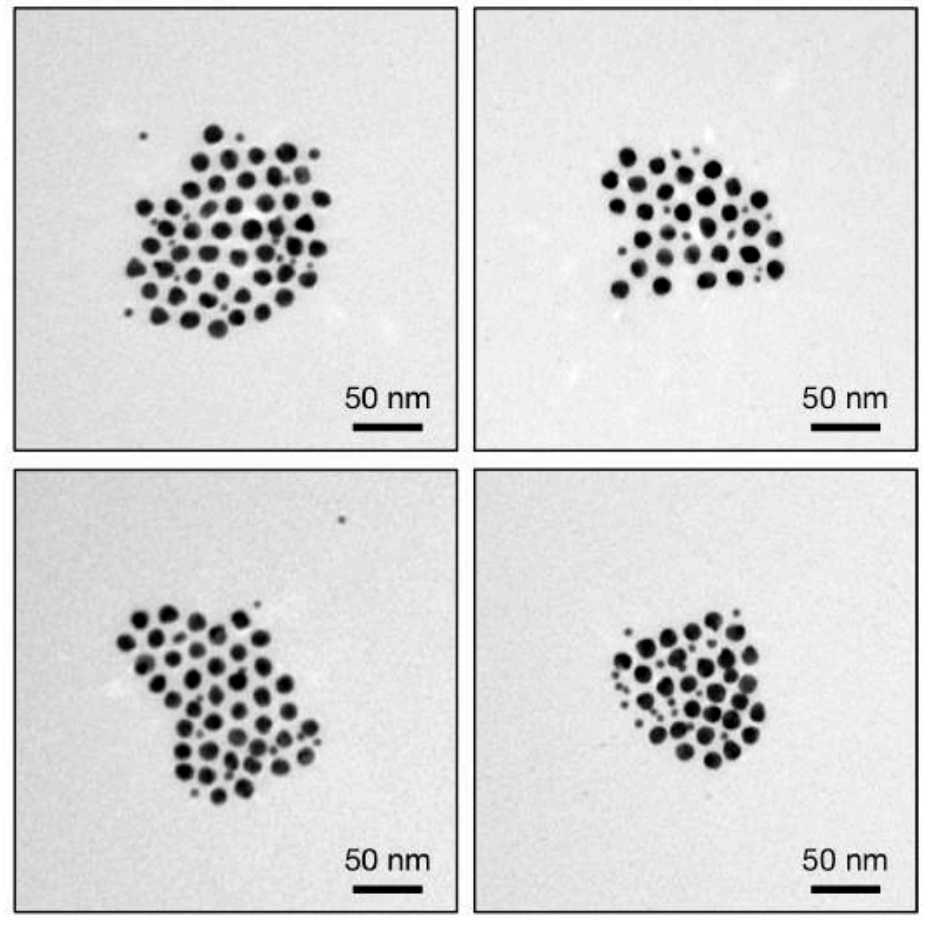

Figure S7. Additional TEM images for the alternate-type hetero-assembly of fully matched dsDNA-AuNPs. 

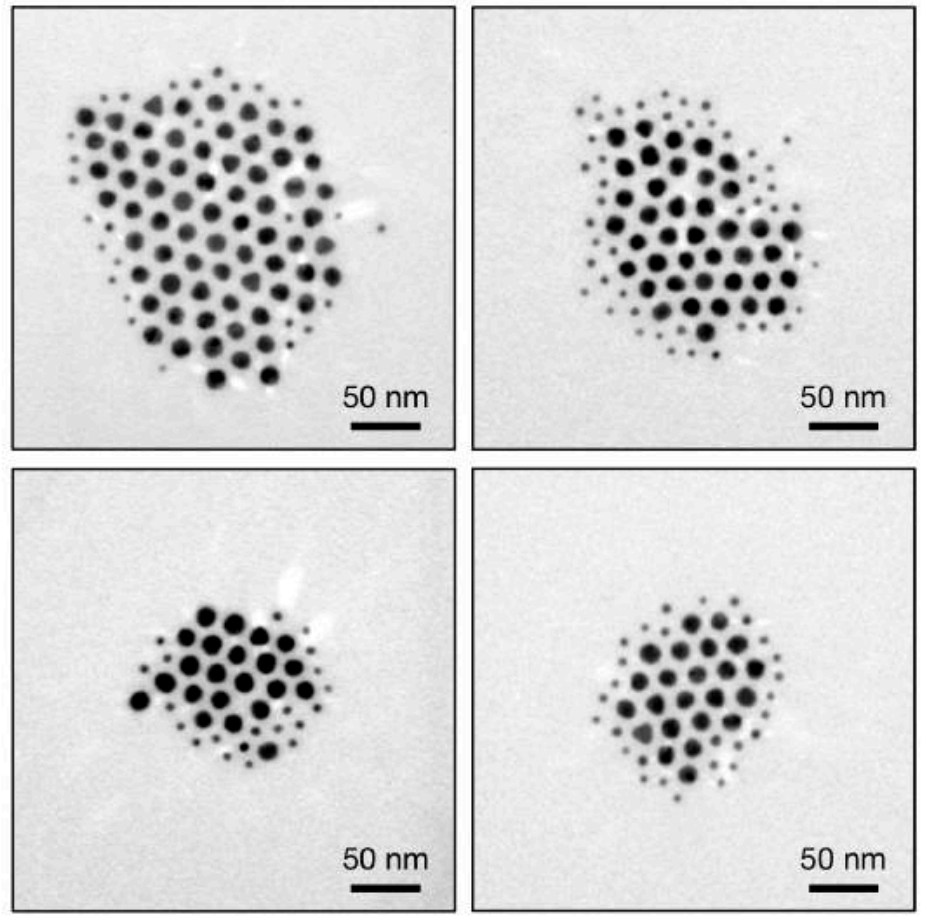

Figure S8. Additional TEM images for the block-type hetero-assembly of fully matched dsDNA-AuNPs. 

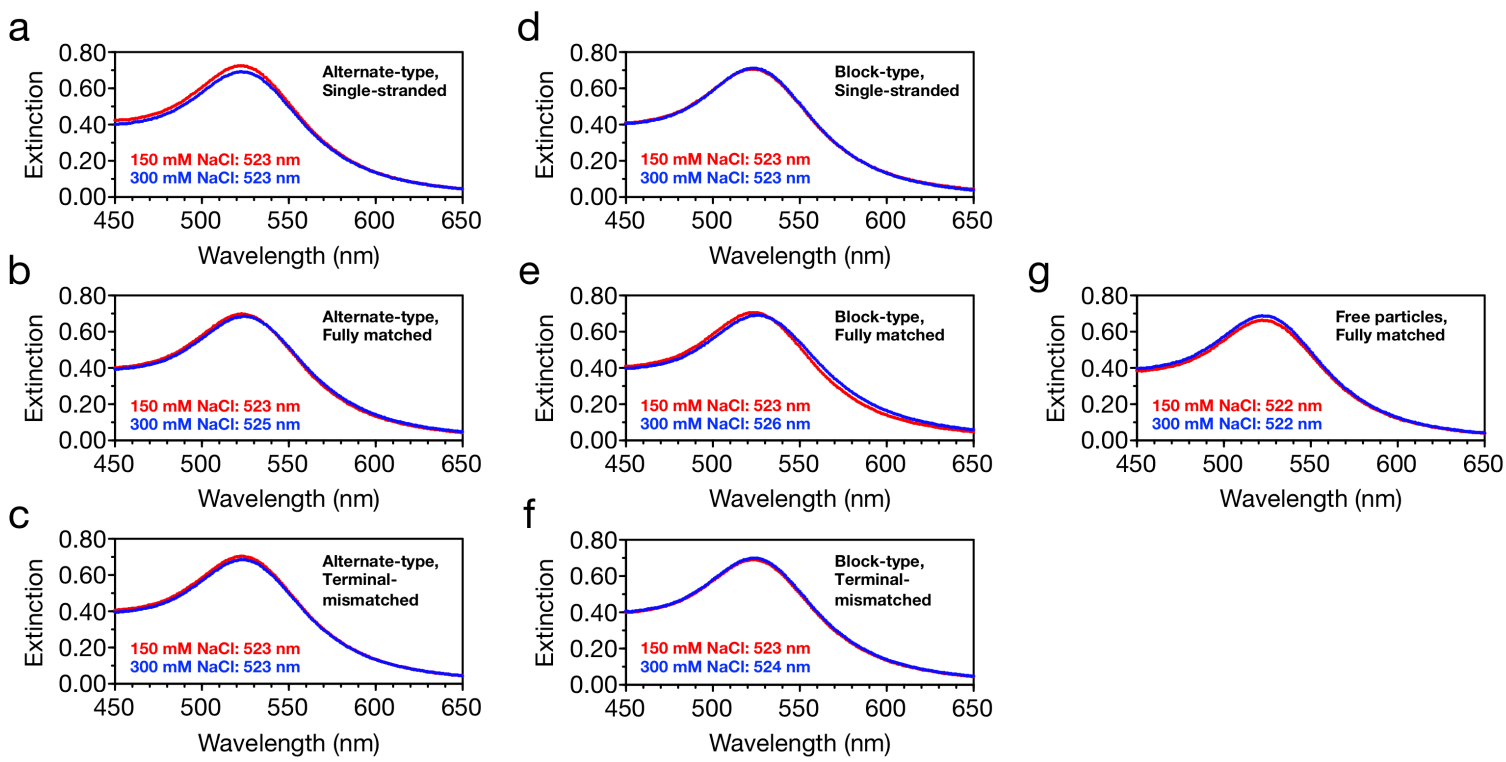

Figure S9. Extinction spectra for $(\mathrm{a}-\mathrm{c})$ the alternate-type DNA-AuNP hetero-assembly, (df) the block-type DNA-AuNP hetero-assembly, and (g) the mixture of the fully matched dsDNA-AuNPs with diameters of 5 and $15 \mathrm{~nm}$, in the presence of $150 \mathrm{mM} \mathrm{NaCl}$ (red) or $300 \mathrm{mM} \mathrm{NaCl}$ (blue) at room temperature. The surface-grafted DNA was single-stranded (a, d), fully matched (b, e, g), and terminal-mismatched (c, f). 